\title{
STUDI KAPASITAS ADSORPSI-REDUKSI ION Au(III) PADA ASAM HUMAT HASIL ISOLASI DARI TANAH GAMBUT RAWA PENING
}

\section{STUDY OF ADSORPTION-REDUCTION CAPACITY OF Au(III) ON HUMIC ACID FROM RAWA PENING PEAT SOIL}

\author{
Dian Prasasti ${ }^{1}$, Sri Juari ${ }^{2}$, Sri Sudiono ${ }^{2}$ \\ Fakultas Farmasi Universitas Ahmad Dahlan \\ Jl. Prof. Dr. Supomo Yogyakarta, Telp. (0274) 379418
}

\section{Abstrak}

Isolasi asam humat dan aplikasinya untuk adsorpsi-reduksi ion Au(III) telah dilakukan. Asam humat diisolasi dari tanah gambut yang diambil dari Rawa Pening, Jawa Tengah. Isolasi asam humat dari tanah gambut didasarkan pada metode ekstraksi tradisional basa. Isolasi asam humat dilakukan dengan mengekstraksi asam humat dari tanah gambut dengan 0,1 $\mathrm{M} \mathrm{NaOH}$ dan mengendapkan dengan 0,1 $\mathrm{M} \mathrm{HCl}$ kemudian dilakukan pencucian dengan 0,1 M HCl/0,3 M HF 1/1. Asam humat dikarakterisasi dengan spektroskopi Fourier-Transform Infrared (FTIR) kemudian diaplikasikan untuk adsorpsi-reduksi ion Au(III). Kapasitas adsorpsi menggunakan model isoterm adsorpsi terhadap proses adsorpsi reduksi ion Au(III) juga telah dipelajari. Logam Au yang terbentuk dikonfirmasi dengan difraktogram XRD dan foto mikroskop optik. Hasil perhitungan kapasitas adsorpsi dengan model isoterm Langmuir asam humat adalah $192 \mathrm{mg} / \mathrm{g}$. Pembentukan logam Au ditunjukkan oleh munculnya puncak pada $2 \theta=38,44$, dan 64 dalam difraktogram XRD.

Kata kunci : asam humat, Au(III), adsorpsi, reduksi, kapasitas adsorpsi, isoterm adsorpsi

\footnotetext{
${ }^{2}$ Fakultas MIPA UGM
} 


\section{Abstract}

Isolation of peat soil humic acid and its application for adsorption-reduction of Au(III) have been conducted. Humic acid was isolated from peat soil that was collected from Rawa Pening, Central Java. Isolation of humic acid from peat soil was based on conventional alkaline extraction. Humic acid was extracted from peat soil with $\mathrm{NaOH}$ $0.1 \mathrm{M}$, then precipitated with $0.1 \mathrm{M} \mathrm{HCl}$, and purified with $0.1 \mathrm{M} \mathrm{HCl} / 0.3 \mathrm{M} \mathrm{HF}$ 1/1. The isolated humic acid was characterized by FTIR spectroscopy, then applied for adsorption reduction of Au(III). Isothermic adsorption capacity on adsorption reduction process of Au (III) also were studied. The gold metal formed was confirmed by XRD diffractogram, and photo optical microscope. The adsorption capacity with Langmuir isothermic model for humic acid was $192 \mathrm{mg} / \mathrm{g}$. Peaks of gold particles in the difractogram are $2 \theta=38,44$, and 64 .

Keywords: humic acid, Au(III), adsorption, reduction, adsorption capacity, adsorption isotherm

\section{PENDAHULUAN}

Emas adalah salah satu logam berat dengan nilai ekonomis tinggi sehingga selalu menarik untuk dieksplorasi (Watling, 2007). Di bumi, emas ditemukan dalam bentuk logam (native) yang terdapat dalam retakan-retakan batuan kwarsa dan dalam bentuk mineral. Emas juga ditemukan dalam bentuk emas alluvial yang terbentuk karena proses pelapukan batuan-batuan yang mengandung emas (gold-bearing rocks). Kelimpahan relatif emas dalam kerak bumi diperkirakan sebesar $0,004 \mathrm{~g} /$ ton, termasuk sekitar $0,001 \mathrm{~g} /$ ton terdapat di perairan laut (Rusdiarso, 2007). Emas selain sebagai perhiasan juga memiliki banyak manfaat di bidang kesehatan, seperti untuk kecantikan, penyusun nanopartikel dalam pengobatan kanker, digunakan dalam industri farmasi, dan lain-lain.
Dalam barang-barang elektronik seperti tv, radio, hp, dan komputer selalu mengandung emas. Perusahaan Jepang, Yokohama Metal Co Ltd. pernah melakukan penelitian dan menemukan bahwa satu ton bahan tambang emas setelah diolah, rata-rata hanya menghasilkan 5 gram emas, sementara 1 ton ponsel bekas bisa menghasilkan 150 gram emas atau lebih. Pabrik daur ulang ponsel di Jepang, Eco-system Recycling Co., menghasilkan emas batangan antara $199.58-299.37 \mathrm{~kg} /$ bulan yang nilainya berkisar US $\$ 5,9$ juta - US $\$ 8,8$ juta. Hasil yang hampir sama dengan sebuah penambangan emas skala kecil, dengan resiko dan modal yang lebih kecil (Anonim, 2008).

Metode isolasi emas yang banyak digunakan adalah metode sianida (Hiskey, 1985) dan metode amalgamasi dengan menggunakan merkuri (Lee, 1994). Sianida telah digunakan sebagai 
material pengekstraksi emas selama lebih dari 100 tahun, dikarenakan murah (Watling, 2007). Merkuri dan sianida dapat mengendap di perairan dan masuk ke rantai makanan apabila masuk ke dalam tubuh manusia melalui penggunaan air dan hasil-hasil perairan yang dimanfaatkan manusia. Akibatnya, terjadi penumpukan logam berat dalam jaringan tubuh manusia, sehingga secara perlahan dapat menimbulkan kerusakan permanen pada organ tubuh. Bahkan secara kronis dapat menyebabkan kematian.

Metode alternatif yang dapat digunakan adalah adsorpsi. Metode ini murah, mudah dioperasikan, sederhana, serta kapasitasnya besar (Thomas dan Crittenden, 1998). Adsorpsi didasarkan pada interaksi ion logam dengan gugus fungsional yang ada pada permukaan adsorben melalui interaksi pembentukan kompleks dan biasanya terjadi pada permukaan padatan yang kaya gugus fungsional seperti $-\mathrm{OH}$, - NH, $-\mathrm{SH}$, dan $-\mathrm{COOH}$ (Stum dan Morgan, 1996). Adsorben konvensional dalam proses hidrometalurgi emas adalah karbon aktif (Laatikainen dan Paatero, 2005). Karbon aktif mudah dipreparasikan dan memiliki kapasitas adsorpsi yang cukup tinggi terhadap emas, namun memiliki kelemahan, yaitu emas sulit untuk didesorpsi atau dilepaskan dari permukaan karbon aktif (Nakbanponte dkk., 2002). Berbagai adsorben selain karbon aktif juga telah banyak dilakukan, seperti resin kitosan (Ramesh dkk., 2008), persimmon tanning gel (Nakajima dkk., 2003), novel tanning gel (Ogata dan Nakano, 2005), turunan lignofenol (Parajuli dkk., 2009), turunan fenol (Hamamoto dkk., 2009), dietilaminoetil-selulosa (Tasdelen dkk., 2008), dan humin (Dewi, 2010).

Hamamoto dkk. (2009) telah melakukan reduksi ion emas menjadi logam emas menggunakan turunan fenol dan menunjukkan hasil bahwa gugus hidroksil pada senyawa turunan fenol bekerja secara efisien dalam mereduksi ion emas menjadi logam emas.

Asam humat merupakan salah satu fraksi tanah gambut yang larut dalam basa tetapi larut dalam asam. Asam humat mengandung gugus fungsional $-\mathrm{COOH}$ dan $-\mathrm{OH}$ sehingga dapat digunakan sebagai adsorben untuk logam maupun senyawa organik.

Banyaknya limbah elektronik yang dihasilkan dan mengingat dampak negatif yang ditimbulkan, maka pada penelitian ini akan dipelajari asam humat untuk adsorpi reduksi ion $\mathrm{Au}(\mathrm{III})$ dengan perhitungan kapasitas adsorpsi-reduksi.

\section{METODE PENELITIAN}

\section{Bahan}

Tanah gambut dari Rawa Pening, Jawa Tengah, $\mathrm{HCl}$ p.a, $\mathrm{HF}$ p.a, $\mathrm{NaOH}$ p.a, $\mathrm{KOH}$ p.a, $\mathrm{KCl}$ p.a, larutan $\mathrm{HAuCl}_{4}$ 1000 ppm (buatan Sri Sudiono, M.Si), aquades (laboratorium Kimia Dasar UGM), kertas saring Whatman 42, dan gas $\mathrm{N}_{2}$ (CV. Perkasa)
Alat
Peralatan yang digunakan dalam penelitian ini antara lain hot plate dan 
stirrer, neraca analitik (Shimadzu), Centrifuge (Kokusan tipe H-107), lumpang dan mortal agat, $\mathrm{pH}-$ meter (Horiba $\mathrm{pH}$ meter F-52), oven (Fischer Scientific model $655 \mathrm{~F}$ ), ayakan tepung dan ayakan 200 mesh, peralatan analisis meliputi spektrofotometer inframerah (Shimadzu FTIR-8201 PC), mikroskop optik kamera (Nikon SMZ 1500 +Nikon Digital Camera DXM 1200C), difraktometer sinar-X (Shimadzu XRD-6000), dan spektrofotometer serapan atom (Perkin Elmer 3110), serta alat penunjang berupa alat-alat gelas dan plastik laboratorium.

\section{Jalannya Penelitian}

Isolasi Asam Humat : Tanah gambut yang berasal dari rawa pening dikeringkan pada suhu kamar, kemudian dipisahkan dari ranting dan akar. Tanah tersebut digerus dan diayak dengan ayakan tepung. Seratus gram tanah yang telah halus diisolasi dengan $\mathrm{NaOH} 0,1 \mathrm{M}$ dengan cara digojok selama 24 jam di bawah kondisi nitrogen. Padatan dan filtrat dipisahkan dengan disaring dengan kain dan disentrifuge $2000 \mathrm{rpm}$ selama 20 menit. Filtrat yang terbentuk kemudian diendapkan dengan $\mathrm{HCl} 0,1 \mathrm{M}$ hingga $\mathrm{pH} \approx 1$. Endapan dipisahkan dari filtrat dengan disentrifuge $2000 \mathrm{rpm}$ selama 20 menit kemudian dikarakterisasi dengan spektrometer FTIR.

Pemurnian Asam Humat : Asam humat dimurnikan dengan dilarutkan dengan $\mathrm{KOH}$ 0,1 $\mathrm{M}$ dan ditambahkan garam $\mathrm{KCl}$ hingga $\left[\mathrm{K}^{+}\right]=0,3 \mathrm{M}$. Larutan ini digojok 24 jam di bawah kondisi atmosfer nitrogen. Filtrat dan endapan yang terbentuk dipisahkan dengan disentrifuge $2000 \mathrm{rpm}$ selama 20 menit. Filtrat yang didapat kemudian diendapkan dengan $\mathrm{HCl} 0,1 \mathrm{M}$ hingga $\mathrm{pH} \approx 1$. Endapan dipisahkan dari filtratnya dengan disentrifuge $2000 \mathrm{rpm}$ selama 20 menit. Endapan dicuci empat kali dengan larutan $\mathrm{HCl} 0,1 \mathrm{M}: \mathrm{HF}$ $0,3 \mathrm{M}=1: 1$. Pencucian dilakukan dengan wadah plastik. Hasil pencucian kemudian dicuci dengan aquades. Endapan hasil pemurnian kemudian dioven pada suhu $40{ }^{\circ} \mathrm{C}$. Asam humat yang telah murni dikarakterisasi dengan spektrometer FTIR.

\section{Penentuan Model Isoterm Adsorpsi-Reduksi Ion Au(III) :} Sepuluh miligram asam humat dicampurkan dengan $10 \mathrm{~mL}$ larutan $\mathrm{AuCl}_{4}{ }^{-}$dengan konsentrasi divariasikan $5,10,15,30,45,60,80,100,150,200$, 300 , dan 400 ppm pada pH 2. Campuran kemudian digojok 24 jam. Campuran kemudian disaring dengan kertas saring whatman 42. Filtrat kemudian dianalisis dengan spektrofotometer serapan atom (SSA).

Karakterisasi Asam Humat Pasca Adsorpsi : Asam humat setelah proses adsorpsi dikarakterisasi dengan spektrometer FTIR，XRD, dan difoto di bawah mikroskop perbesaran 112,5. 


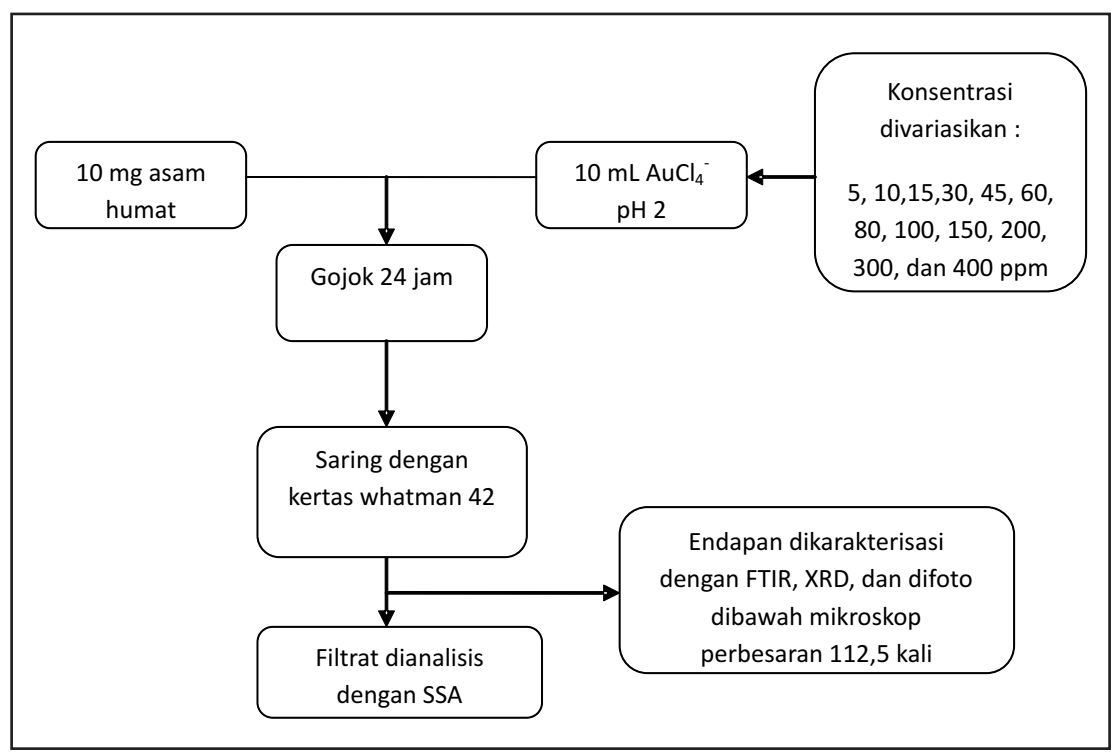

Gambar 1. Bagan penentuan model isoterm adsorpsi-reduksi ion Au(III)

\section{HASIL DAN PEMBAHASAN}

\section{Isolasi dan Pemurnian Asam Humat}

Asam humat yang digunakan dalam penelitian ini diisolasi dari tanah gambut Rawa Pening, Jawa Tengah. Proses isolasi menggunakan metode konvensional ekstraksi alkali. Asam humat larut dalam basa tetapi tidak larut dalam asam, sehingga isolasi dengan ekstraksi menggunakan basa kuat $\mathrm{NaOH}$ kemudian diendapkan dengan $\mathrm{HCl}$. Proses isolasi dengan basa dilakukan dengan pengaliran gas $\mathrm{N}_{2}$ untuk mengusir $\mathrm{O}_{2}$ dalam sistem agar tidak terjadi reaksi auotooksidasi pada tanah gambut oleh basa $\mathrm{NaOH}$. Asam humat kotor yang diperoleh kemudian dimurnikan dengan melarutkan dalam $\mathrm{KOH}$ dan pengaliran gas $\mathrm{N}_{2}$, kemudian diendapkan kembali dengan $\mathrm{HCl}$. Setelah proses pengendapan dengan $\mathrm{HCl}$, asam humat yang diperoleh dicuci dengan campuran $0,1 \mathrm{M} \mathrm{HCl}: 0,3 \mathrm{M} \mathrm{HF} \mathrm{1:1.} \mathrm{Asam} \mathrm{humat}$ dilarutkan kembali dengan $\mathrm{KOH}$ untuk memisahkan dengan senyawa humin yang terikut saat proses ekstraksi. Pencucian dengan $\mathrm{HCl} / \mathrm{HF}$ untuk menghilangkan pengotor anorganik maupun pengotor organik terutama silika (tanah).

\section{Karakterisasi Asam Humat Hasil Isolasi dengan FTIR}

Menurut Stevenson (1994), senyawa humat memiliki gugus fungsional utama seperti $-\mathrm{OH}$, $-\mathrm{COOH}$, kuinon, aromatik, dan alifatik.

Spektra IR asam humat hasil isolasi pada Gambar 2 menunjukkan beberapa puncak serapan yang karakteristik. Serapan yang melebar dan kuat di daerah $3300 \mathrm{~cm}^{-1}$ merupakan vibrasi ulur gugus $-\mathrm{OH}$ dan menunjukkan adanya ikatan hidrogen. Puncak serapan $2900 \mathrm{~cm}^{-1}$ merupakan vibrasi ulur $\mathrm{C}-\mathrm{H}$ alifatik. Puncak di 
daerah $1700 \mathrm{~cm}^{-1}$ merupakan vibrasi ulur $\mathrm{C}=\mathrm{O}$ dari $\mathrm{COOH}$ dan keton. Puncak $1610 \mathrm{~cm}^{-1}$ merupakan serapan $\mathrm{C}=\mathrm{C}$ aromatik dan vibrasi ulur asimetrik $\mathrm{C}=\mathrm{O}$. Puncak di daerah $1250 \mathrm{~cm}^{-1}$ merupakan vibrasi ulur C-O. Puncak di daerah 1460 $\mathrm{cm}^{-1}$ merupakan serapan $\mathrm{C}-\mathrm{H}$ dari $\mathrm{CH}_{2}$ ataupun $\mathrm{CH}_{3}$. Puncak di daerah 13902 merupakan serapan vibrasi bending $\mathrm{C}-\mathrm{H}$ dari $\mathrm{CH}_{3}$. Spektra IR asam humat hasil penelitian sesuai dengan Stevenson (1994), yaitu munculnya puncak-puncak yang karakteristik pada bilangan gelombang 3400, 2900, 1720, 1600, dan $1200 \mathrm{~cm}^{-1}$.

Spektra FTIR asam humat sebelum dan setelah dilakukan pencucian terlihat beberapa perbedaan. Setelah dilakukan pencucian, ada puncak-puncak yang hilang dan juga ada puncak yang mengalami pergeseran. Pergeseran bilangan gelombang 3402 $\mathrm{cm}^{-1}$ ke $3371 \mathrm{~cm}^{-1}$ dan bertambah lebarnya serapan di daerah tersebut setelah dilakukan pencucian menunjukkan bahwa setelah dilakukan pencucian, ikatan hidrogen dalam asam humat semakin bertambah. Bertambah besarnya serapan di bilangan gelombang sekitar $1700 \mathrm{~cm}^{-1}$ menunjukkan bertambahnya serapan gugus $-\mathrm{C}=\mathrm{O}$ dari $-\mathrm{COOH}$. Sebelum pencucian gugus - $\mathrm{COOH}$ berinteraksi dengan logam, dan setelah pencucian logam-logamnya terlepas dari asam humat. Hilangnya serapan Si-O pada bilangan gelombang $1080 \mathrm{~cm}^{-1}$ mengindikasikan berkurangnya silika dalam asam humat yang melekat. Hilangnya serapan pada daerah di bawah $1000 \mathrm{~cm}^{-1}$ menunjukkan bahwa berkurangnya logam-logam dan silika yang terikat pada asam humat hasil isolasi.

\section{Isoterm Adsorpsi-Reduksi Au(III) pada Asam Humat}

Kapasitas adsorpsi-reduksi $\mathrm{Au}$ (III) pada asam humat ditentukan

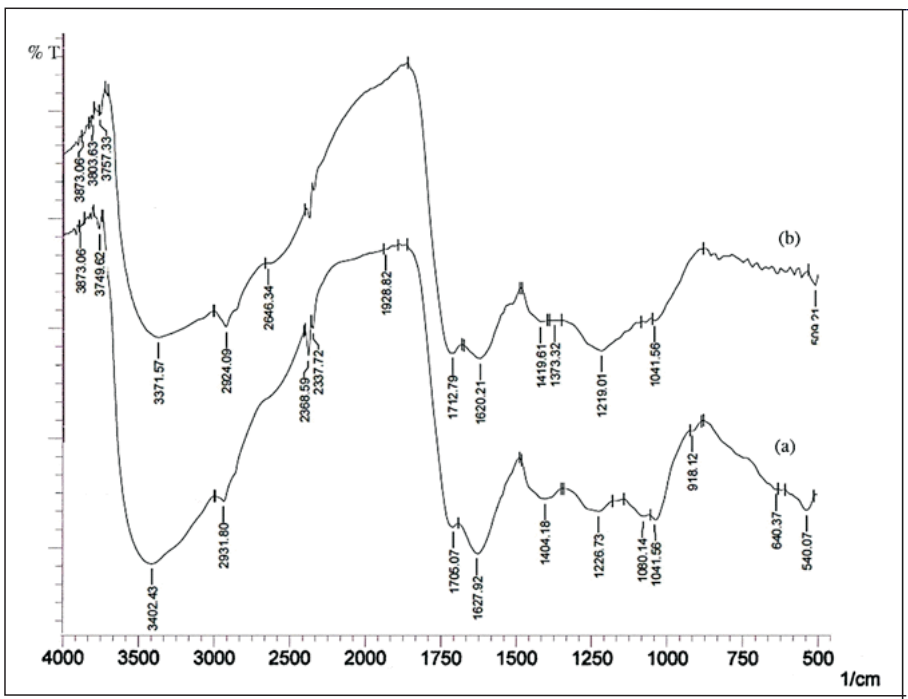

Gambar 2. Spektra FTIR asam humat : (a) asam humat kotor; (b) asam humat pemurnian 
menggunakan isoterm adsorpsi. Model isoterm adsorpsi yang digunakan isoterm Freundlich dan isoterm Langmuir. Persamaan isoterm Freundlich digunakan untuk menjelaskan proses adsorpsi non ideal pada permukaan yang heterogen. Heterogenitas dapat disebabkan oleh adanya perbedaan gugus fungsional pada permukaan adsorben. Isoterm Langmuir mengasumsikan bahwa adsorpsi yang terjadi hanya merupakan adsorpsi satu lapis saja (monolayer). Apabila jumlah situs aktif pada permukaan adsorben sudah tertutup oleh adsorbat, maka proses adsorpsi selanjutnya akan terhalangi.

Penentuan model isoterm Freundlich dilakukan dengan membuat kurva linier $\log$ qe vs $\log$ Ce, sedangkan model isoterm Langmuir dilakukan dengan membuat kurva linier Ce/qe vs Ce.

Dari data hasil penelitian terlihat bahwa adsorpsi ion $\mathrm{Au}(\mathrm{III})$ oleh asam humat mengikuti model isoterm Langmuir. Situs aktif pada permukaan asam humat dapat dianggap homogen, tidak ada interaksi antara molekul adsorbat (ion $\mathrm{Au}(\mathrm{III})$ ), dan adsorpsi $\mathrm{Au}(\mathrm{III})$ pada asam humat hanya terjadi pada satu lapis (monolayer). Kapasitas adsorpsi asam humat dalam mengadsorp $\mathrm{Au}(\mathrm{III}) \mathrm{maksimum} 192 \mathrm{mg} / \mathrm{g}$, artinya 1 gram asam humat mampu mengadsorpsi $192 \mathrm{mg}$ emas, dengan nilai $\mathrm{K}_{\mathrm{L}} \quad 0,265$ $\mathrm{L} / \mathrm{mg}$.

Tabel I. Hasil perhitungan kapasitas adsorpsi-reduksi asam humat

\begin{tabular}{cccccc}
\hline & Freundlich & \multicolumn{3}{c}{ Langmuir } \\
\hline $\mathrm{KF}(\mathrm{mg} / \mathrm{g})$ & $\mathrm{N}$ & $\mathrm{R}$ & qmax $(\mathrm{mg} / \mathrm{g})$ & $\mathrm{KL}(\mathrm{L} / \mathrm{mg})$ & $\mathrm{R}$ \\
27,384 & 2,138 & 0,833 & 192 & 0,265 & 0,994 \\
\hline
\end{tabular}
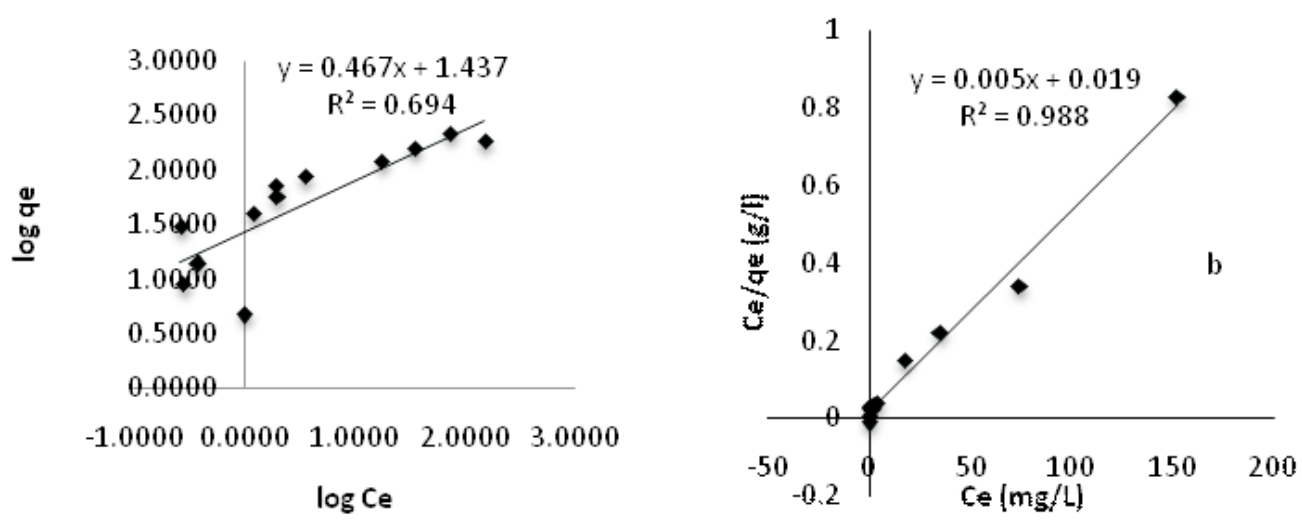

Gambar 3. Grafik adsorbsi isoterm Freundlich (a) dan Langmuir (b) asam humat 


\section{Karakterisasi Asam Humat Setelah Proses Adsorpsi-Reduksi}

Asam humat setelah proses adsorpsi-reduksi dikarakterisasi dengan foto mikroskop, FTIR, dan XRD.

Hasil foto mikroskop asam humat dan asam humat setelah proses adsorpsi-reduksi terlihat pada gambar 4 . Perbesaran 112,5 kali terlihat adanya logam $\mathrm{Au}(0)$ pada asam humat. Hal ini membuktikan terjadinya proses reduksi hampir di seluruh permukaan asam humat.
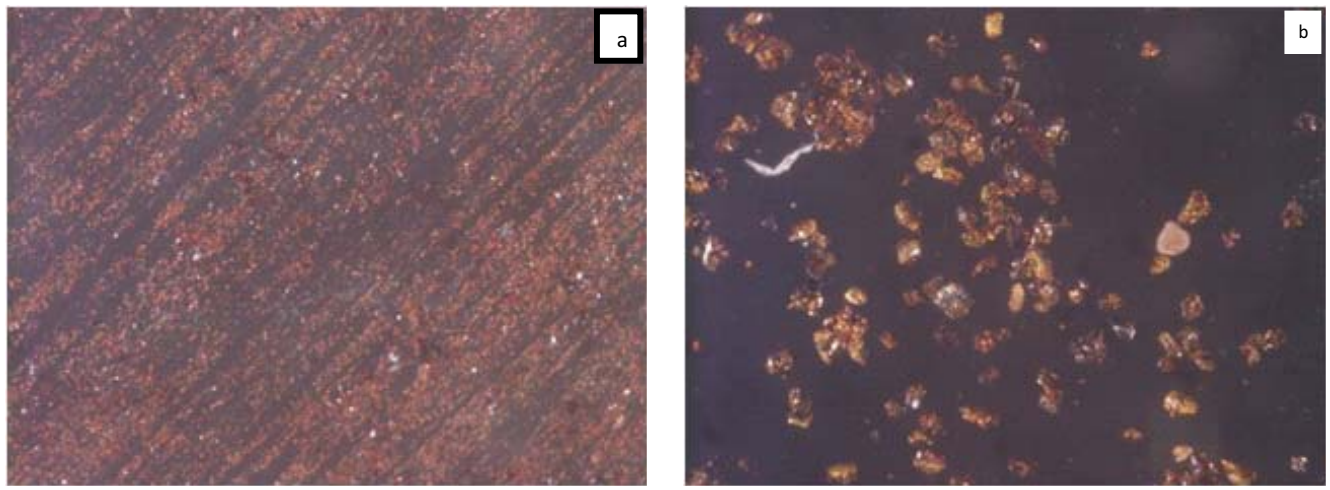

Gambar 4. Hasil foto mikroskop asam humat (a) dan asam humat setelah proses adsorpsi-reduksi (b)

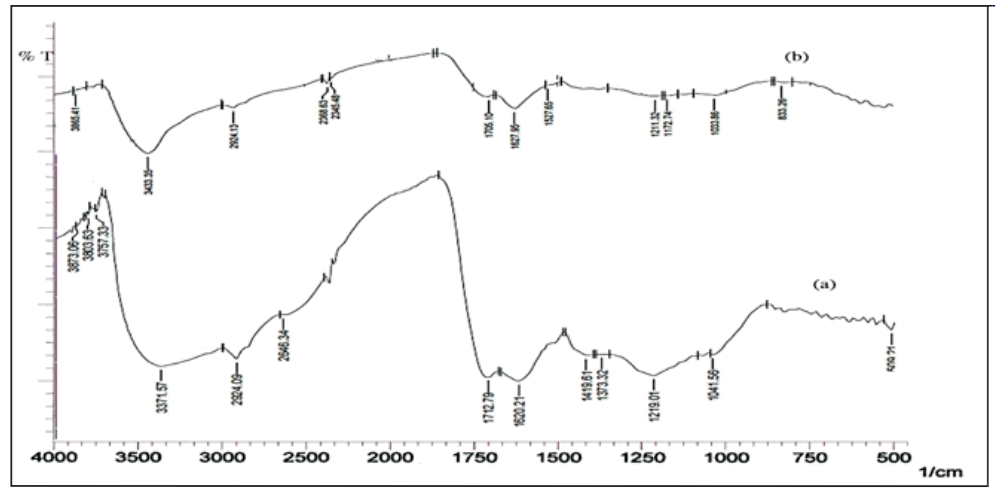

Gambar 5. Spektra IR asam humat: (a) sebelum berinteraksi dengan ion Au(III) (asam humat); (b) setelah berinteraksi dengan ion $\mathrm{Au}(\mathrm{III})$ 
nya serapan pada bilangan gelombang $1033 \mathrm{~cm}^{-1}$ dan $833 \mathrm{~cm}^{-1}$ pada asam humat setelah proses adsorpsi, menunjukkan adanya logam yang terikat pada asam humat.

Hasil difraktogram sinar $\mathrm{X}$ yang terlihat pada Gambar 6 menunjukkan perbedaan yang sangat jelas antara asam humat sebelum dan sesudah proses adsorpsi-reduksi. Asam humat berstruktur amorf, setelah proses adsorpsi ion $\mathrm{Au}(\mathrm{III})$ muncul puncak karakteristik dari logam emas di daerah 2 theta 38,44 , dan 64 pada difraktogram sinar $\mathrm{X}$ menunjukkan adanya logam $\mathrm{Au}(0)$.

Ketiga puncak karakteristik tersebut sama dengan pola puncak dari difraktogram emas yang dihasilkan oleh Nakajima dkk. (2003) dan Parajuli dkk. (2008). Ketiga puncak karakteristik tersebut menunjukkan bahwa refleksi bidang [111], [200], dan [220] yang merupakan struktur dari face-centered cubic dengan $\mathrm{a}=4,06 \AA$ A Keberadaan $\mathrm{Au}(0)$ pada asam humat setelah adsorpsi menunjukkan bahwa ion $\mathrm{Au}(\mathrm{III})$ tidak hanya teradsorpsi, tetapi juga tereduksi menjadi logam $\mathrm{Au}(0)$.

Perbandingan kapasitas adsorpsi beberapa material adsorben untuk adsorpsi emas ditunjukkan pada Tabel II. Pada tabel tersebut terlihat bahwa adsorben yang digunakan dalam penelitian ini (asam humat) memiliki kapasitas adsorpsi lebih tinggi dibandingkan adsorben yang lain.

\section{KESIMPULAN}

Asam humat dapat diisolasi dari tanah gambut Rawa Pening dengan melarutkan dalam basa dan mengendapkan dengan asam. Hasil perhitungan kapasitas adsorpsi-reduksi ion $\mathrm{Au}(\mathrm{III})$ pada asam humat dengan model isoterm Langmuir adalah $192 \mathrm{mg} / \mathrm{g}$. Hasil karakterisasi

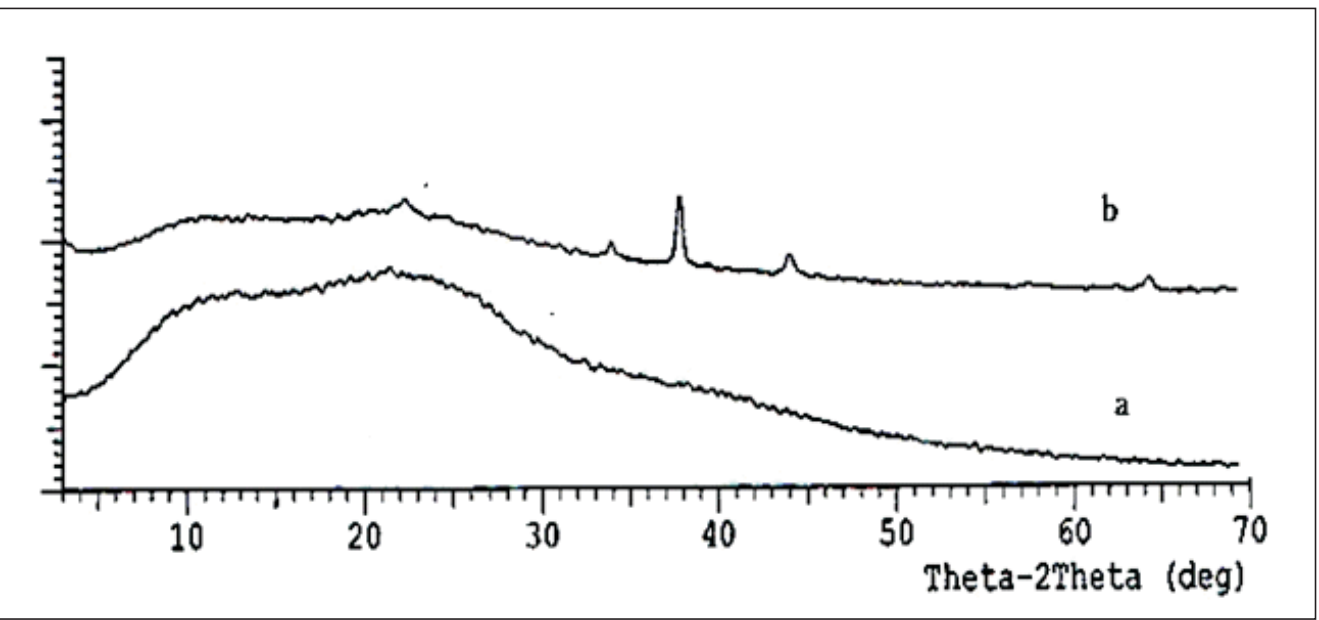

Gambar 6. Difraktogram asam humat: (a) sebelum berinteraksi dengan ion Au(III); (b) setelah berinteraksi dengan ion $\mathrm{Au}(\mathrm{III})$ 
Tabel II. Perbandingan kapasitas adsorpsi beberapa material adsorben terhadap emas

\begin{tabular}{|l|c|l|}
\hline \multicolumn{1}{|c|}{ Adsorben } & Kapasitas(mg/g) & \multicolumn{1}{c|}{ Referensi } \\
\hline Asam humat & 192 & Hasil penelitian, 2012 \\
\hline Humin & 71,43 & Dewi, 2010 \\
\hline Humin teresterifikasi & 71,43 & Dewi, 2010 \\
\hline C vulgaris & 28,17 & Nakbanpote dkk., 2002 \\
\hline Alfalfa biomass & 35,97 & Gamez dkk., 2003 \\
\hline Abu sekam & 50,50 & Nakbanpote dkk., 2002 \\
\hline
\end{tabular}

dengan XRD menunjukkan terjadinya proses reduksi $\mathrm{Au}(\mathrm{III})$ menjadi logam $\mathrm{Au}(0)$ pada ketiga adsorben, yaitu pada $2 \theta=38,44$, dan 64 yang merupakan karateristik dari logam Au.

\section{DAFTAR PUSTAKA}

Anonim, 2008, Yuk Menghitung Emas di Ponsel Bekas, kompas.com., diakses tanggal 5 April 2011.

Dewi, S.R., 2010, Aplikasi Humin dari Tanah Gambut untuk Adsorpsi Reduksi $\mathrm{AuCl}_{4}^{-}$dalam Larutan, Tesis, Universitas Gajah Mada, Yogyakarta.

Gamez, G., Gardea-Torresdey, J.L., Tiemann, K.J., Parsons, J., Dokken, K., dan Yacaman, M.J., 2003, Recovery of Gold (III) from Multi-elemental Solutions by Alfafa Biomass, Adv. Environ. Res., 7, 563-571.

Hamamoto, K., Kawakita, H., Ohto, K., dan Inoue, K., 2009, Polymerization of Phenol Derivatives by Reduction of Gold Ions to Gold Metal, React. Funct. Polym, 69, 694-697.
Hiskey, J.B., 1985., Gold and Silver Extraction : the Application of Heap-Leaching Cyanidation., Arizona Bureau of Geology and Mineral Technology Field Notes, 15 (4), 1-5.

Laatikainen, M. dan Paatero, E., 2005. Gold Recovery from Chloride Solutions with XAD-7 : Competitive Adsorption of $\mathrm{Fe}$ (III) and Te (IV)., Hydrometallurgy., 79., $154-171$.

Lee J. D., Concise Inorganic Chemistry $4^{\text {th }} \mathrm{ed}$., Chapman \& Hall., London.

Nakajima A., Ohe K., Baba Y., dan Kijima T., 2003, Mechanism of Gold Adsorption by Persimmon Tannin Gel, Anal. Sci., 19, 1075-1077.

Nakbanponte, W., Thiravetyan, P., dan Kalambaheti, C., 2002., Comparison of Gold Adsorption by Chlorella Vulgaris, Rice Husk and Activated Carbon., Minerals Engineering., 15., 549-552.

Ogata T., dan Nakano Y., 2005, Mechanism of Gold Recovery from Aqueous Solutions Using a Novel Tannin Gel Adsorbent 
Synthesized from Natural Condensed Tannin, Water Res., 39, 4281-4286.

Parajuli, D., Adhikari, C.R., Kawakita., H., Kajiyama K., Ohto, K., dan Inoue, K., 2008, Reduction and Accumulation of $\mathrm{Au}$ (III) by Grape Waste : A Kinetic Approach, React. Funct. Polym., 68, 1194-1199.

Parajuli D., Adhikari C.R., Kawakita H., Yamada, S., Ohto K., dan Inoue K., 2008, Chestnut Pellicle for The Recovery of Gold, Bioresour. Technol., 100, 1000-1002 .

Parajuli, D., Khunathai, K., Adhikari, C.R., Inoue, K., Ohto, K., Kawakita, H., Funaoka, M., dan Hirota, K., 2009, Total Recovery of Gold, Palladium, and Platinum Using Lignophenol Derivative, Miner. Eng., 22, 1173-1178.

Ramesh, A., Hasegawa, H., Sugimoto, W., Maki, T., dan Ueda, K., 2008, Adsorption of Gold(III), Platinum(IV) and Palladium(II) onto Glycine Modified Crosslinked Chitosan Resin, Bioresour. Technol., 772, 347-355.

Rusdiarso, B., 2007., Studi Ekstraksi Pelarut Emas (III) dalam Larutan
Konsentrat Tembaga PT Freeport dengan 8-Metilxantin., Berkala MIPA UGM., 17 (2), 15-21.

Stevenson, F.J., 1994, Humic Chemistry Genesis, Composition, Reactions, John Willey \& Sons. Inc, New York.

Stum, W., dan Morgan, J. J., 1996, Aquatic Chemistry : Chemical Equilibria in Natural Water., $3^{\text {rd }}$ ed., John Willey and Sons., Inc., New York.

Tasdelen, C., Aktas, S., Acma, E., dan Guvenilir, Y., 2008, Gold Recovery from Dilute Gold Solutions Using DEAE-cellulose, Hydrometalllurgy, 96, 253-257.

Thomas, W.J. dan Crittenden, B. D., 1998., Adsorption technology and Design., ButterworthHienemann., Oxford.

Watling K. M., 2007., Spectroelectrochemical Studies of Surface Species in the Gold/Thiosulfate System., Thesis., Grffith Science Environment Engineering and Technology., Griffth University, Australia 
